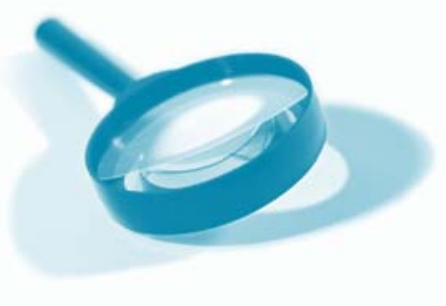

\title{
A case study exploring students' problem-solving strategies in a PBL chemistry task
}

Orla Kelly

School of Education

Plymouth University

Plymouth PL4 8AA

orla.kelly@plymouth.ac.uk

\section{James Lovatt}

School of Education Studies

Dublin City University

Dublin 9, Ireland

james.lovatt@dcu.ie
1

...we need to be more aware of the learning approaches of our students, as well as their subject knowledge, as they enter into higher education through careful scaffolding of such problem-based task.

\begin{abstract}
This paper shares the initial results of a small-scale research study which aimed to investigate the problem solving processes Year 1 undergraduate science students used while undertaking problem-based learning tasks in the chemistry laboratory. A qualitative case study, combining observation and semi-structured interviews, was used to explore learners' experience of the problem-based learning $(P B L)$ task. The literature on problem solving processes of experts generally places importance on domain specific knowledge, developed through experience, for the expert. This is of particular relevance to this study since the students have a range of different prior experiences in the 'chemistry' and 'experimental/practical' domains. Overall, it was shown that students revealed novice-like problem solving strategies and surface approaches to learning. However, one group revealed more expert-like characteristics, coupled with a deep approach, with this group successfully solving the problem. One implication of this study is that we need to be more aware of the learning approaches of our students, as well as their subject knowledge, as they enter into higher education through careful scaffolding of such problem-based task.

\section{Introduction}

Problem and context-based learning continue to be popular strategies for the teaching of chemistry and physics. Such approaches have been found to engage and motivate students and to develop a range of intellectual and transferable skills in the physical sciences ${ }^{1}$. In a recent review of $\mathrm{PBL}^{2}$, it was recognised that additional research into the effects of PBL on students' gains in problem-solving, critical thinking, motivation, and self -regulated learning was needed. It is the problem-solving element of PBL that took the interest of the authors.
\end{abstract}

\section{Problem-solving strategies}

There are many studies that attempt to describe differences between the problem-solving behaviours of experts and novices across a wide range of areas ${ }^{3-6}$. Generally, importance is placed on domain specific knowledge for the expert, which is developed through experience. This is of particular relevance to this study since the students have different prior experiences in the 'chemistry' domain.

One study, by Benner put forward a novice to expert scale for solving problems ${ }^{4}$. This was drawn from research in clinical nursing practice, strongly linked with the Dreyfus and Dreyfus (1980) model ${ }^{5}$. In this Benner recognised the difference between 'know that' and 'know how', with the latter being achieved through experience and that experience is a pre-requisite for expertise. She describes experience as 'the refinement of preconceived notions and theory through encounters with many actual practice situations that add nuances or shades of differences to theory'. However, both the Dreyfus and Benner models have been criticised because of their apparent absence of social structure, referring to the way norms shape the behaviour of people within the social system and/or social knowledge, showing a recognition that knowledge surfaces through dialog, that all knowledge is socially mediated and access to knowledge is by connecting to people that know or know who to contact ${ }^{7}$. This criticism is of particular interest due to the social nature of the learning environment in which this study is situated. 
Elio and Scharf describe the difference between novice and expert problem-solvers in physics ${ }^{6}$. They describe an expert as not only knowing more than a novice, but also by the difference in how they organise their knowledge about a domain and use that knowledge during problem-solving. This is summarised as novice problem-solvers relying on equations, where as experts rely on principles and concepts. Since some of the students who haven't studied chemistry, will have studied physics (or may have studied neither/both), this model was considered important when analysing the approaches to problem-solving of the students in this study.

Many studies have been carried out into problem solving in the

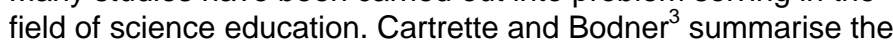
outcomes of these:

'Based on these reports, we have learned that: problem solving success and conceptual understanding are not always coupled; memory structure and organization are constructed in a more sophisticated manner among those problem solvers with more experience in a domain; that our efforts to explicitly teach problem solving strategies do not always meet success; and that problem solving is often accomplished by heavy reliance on algorithms or weak heuristics'. (p. 643)

\section{Students' approaches to learning}

Seminal research investigating how students approached various tasks resulted in the identification of three distinct approaches to learning: Deep, Surface and Strategic ${ }^{8,9}$. The differences in approaches can be distinguished by the intention of the learner where a deep approach relates to the desire to gain a complete understanding of a topic and links it to real world concepts. In this approach the learner will spend much time reading around a topic and it leads to long-term learning. The learner is not bound by assessments or curricular content in this approach. A surface approach is one in which the learner's sole interest is to learn the least amount of material necessary to pass an exam through imitation; this approach is often characterised by short term rote learning where there is no intention to understand the topic and learning is usually short -term. The strategic approach lies in between the two approaches. The strategic learner does have a desire to understand a topic but is also focused on expectations of assessments and curriculum and tries to understand a topic in as much detail as is required by the curriculum. In this approach the learner is keenly aware of assessment requirements and doesn't get distracted reading around a topic like a deep learner. An important outcome of this seminal research revealed that, though students may have a preferred approach to learning, they will adapt their approach depending on the demands of the teaching, learning and assessment environment. A problem-based approach such as the one described in this paper aims to encourage a deep approach ${ }^{10}$.

What this paper offers is an insight into how the problem-solving strategies of our students may be related to theories on how students approach learning, using the deep, strategic, surface model. To this end the following questions are addressed:

- How do students solve problems in groups in the laboratory?

- $\quad$ How do these strategies relate to students' approaches to learning?

\section{Methodology}

This study used a qualitative case study approach, seeking to investigate learners' experiences of a PBL chemistry laboratory. Purposive sampling was used to identify a broad spectrum of students taking an introductory chemistry laboratory module as part of a general first year science programme. The chosen students were following various BSc programmes and had mixed previous chemistry experience. The study involved video recording of each group's initial meeting and final presentation, a structured observation of their in-laboratory experience and, from analysis of the latter, selected students were interviewed regarding their experience of the task. Only the observation and interview data are considered in this initial phase of analysis.

\section{The strategic leamer does}

have a desire to understand a topic but is also focused on expectations of assessments and curric ulum and tries an understand a
topic in as much as is
required by the curric ulum.

The aims of the chemistry laboratory module were to develop practical skills and to link theory and practice through a range of experiments. Approximately 180 students are enrolled in this module, with about 60 students working in the laboratory at any one time. This laboratory module is spread over two semesters, and students' complete 20 laboratory sessions covering inorganic, analytical, physical and organic chemistry. The module is designed to include a range of instructional approaches including expository, context-based and problembased tasks. Each instructional approach is tailored to the associated learning outcomes. The problem-task examined in this study took place in the second semester. It was designed as an opportunity for students to use and put into practice the learning gained in the first semester laboratory sessions. Prior to completing this task students would have completed 4-5 small-scale problem-based tasks. These would have been completed individually or in pairs. For the problem-based task in this study, the students worked in groups of six. 
The PBL activity specific to this research was completed over a two-week period. Students were given background information about a fictional geographical location that contained river systems, and various industrial and residential properties. They were given reports about possible pollution and three unlabelled water samples from the rivers in the region. They had to carry out an analysis on behalf of the Environmental Protection Agency to identify the source of each sample, to investigate pollution reports and to make recommendations. In order to complete the task students had to decide what analysis they wanted to complete and how this would be best achieved in the time allotted. Following the analysis component students had a further week to prepare a report on their analysis and to give an oral presentation of their findings.

Four groups of students were observed in the laboratory and selected students were interviewed to discuss their experience of the task. Two observers attended an earlier laboratory task and completed a pilot study. This was used to get students familiar with being observed and to help devise a consistent structured observation template that could be used to detail the events in the PBL activity including such items as student interactions, questions asked/answered, focus of discussions, time spent on calculations, practical problems, linking theory to practical, relating activities and results to problem etc. Semistructured interviews were used to then elicit students' experiences of completing the PBL task. The interviews were carried out on a one to one basis. Students were selected for interview based on their level and depth of engagement during the practical element of the task. A full range, including those students with the lowest and highest number of engagements, was identified from the observation schedule. Nine out of ten students invited to take part consented to the interview.

Content analysis was achieved by coding the interview transcripts. Firstly, emergent strategies were identified by considering the group's interactions, their plan of action in the laboratory and how they used their findings. Secondly, characteristics relating to deep, strategic and surface approaches were identified by considering motivation, use of resources and work focus.

\section{Findings and discussion}

Overall, the study showed that students relied heavily on the internet for information, which was not surprising. The study supported adoption of group work as students recognised the benefits from this and the associated social aspects of learning. These findings will be explored in combination with the observation and video data in the next phase of analysis, considering further the role of social knowledge and social structure. Additionally, assessment has long been seen as driver for learning and this was also the case in the study.

\section{How do students solve problems in the laboratory?}

Two clear strategies emerged from the interview data. Of the four groups observed, three adopted a very similar 'novice' like strategy, whilst the other adopted a more 'expert' like strategy. With regard to the 'novice' like strategy, students reported a number of common themes. These included:

- organising their knowledge according to apparent/ obvious features of the given problem

- $\quad$ reliance on weak heuristics

- $\quad$ use of provided material

One student, whose group adopted a novice like strategy describes what their group did when they first got into the laboratory.

"We separated into each station and two people would do one test, two do another test and two do the other test on all the samples. It turned out that we should have done the spot test first because we didn't need to test all the water samples".

These findings are similar to those reported by Elio and Scharf in relation to physics problems, who noted that novices tended to suggest solutions and equations soon after reading the problem statement, whereas experts first engage in a kind of qualitative analysis - generating additional useful information about the problem situation that was not explicitly stated in the problem statement ${ }^{6}$. One student, when asked what they would do differently next time they had to solve a problem, begins to recognise such a strategy:

"I would have gone through what the question was first and then picked out points from the question and what I need to look for".

Table 1: The key characteristics from the interviews with relate to the three approaches.

\begin{tabular}{|l|l|l|}
\hline Surface & Strategic & Deep \\
\hline Doing minimal research & Asking tutor for help with calculations & Group discussion \\
\hline 'Plugging' in figures to a formula & Very task focused & Trying to get an idea of what was going on \\
\hline Doing enough to get by & $\begin{array}{l}\text { Sharing the work equally in terms of } \\
\text { practical work }\end{array}$ & Bouncing ideas off each other \\
\hline Approach guided by time & $\begin{array}{l}\text { Working in mixed ability pairs in terms } \\
\text { of their previous chemistry experience }\end{array}$ & Aware of the bigger picture \\
\hline Low interest & Getting results right in the end & $\begin{array}{l}\text { Relating their work back to the original } \\
\text { problem }\end{array}$ \\
\hline
\end{tabular}


Furthermore, they noted that novices organised their knowledge about problems according to surface features of their problem statements (e.g. pulley, inclined plane), while experts organise knowledge based on deeper features of the problem statement, such as the presence of particular forces.

In relation to the group that reported expert-like characteristics, throughout the process they kept relating results back to the original problem and worked constructively as a group discussing results and bouncing ideas off each other. These findings support the criticisms raised by Peña regarding the absence of social structure or social knowledge in other problem-solving models as it is seen here to be integral to 'expert' problem-solving ${ }^{7}$.

The following quote describes how the more 'expert' group approached the task:

"We started off listening to the tutor first of all, then we went and did the spot testing because that saves time because if there's nothing there on the test sample [then there is no need for further testing] - when we did the spot test we wrote down all the answers and then sent everyone off on their separate tasks and we came back at the end and said we'd got this and what the levels were. Then we decided which river was which and our recommendation".

The results suggest that their abilities in problem solving are not related to whether or not they have studied chemistry before since the majority adopted a similar approach despite their varied backgrounds in chemistry. This is contrary to other research which suggests that organisation is constructed in a more sophisticated manner among those problem solvers with more experience in a domain. It is acknowledged that further analysis is needed to explore the differences between the group strategy and an individual's strategy. However, this initial result led to questioning what other factors might give rise to different problem solving abilities ${ }^{1}$.

\section{How do these strategies relate to students' approaches to learning?}

The interview transcripts were analysed in relation to the surface, strategic and deep approaches. Students who take a deep approach have the intention of understanding, engaging with, operating in and valuing the subject. Motivation for students who take a surface approach tends to be that of jumping through the necessary hoops in order to acquire the required mark. The strategic approach is that which students are said to take when they wish to achieve positive outcomes in terms of obtaining a pass mark or better, relative to their ability in the subject, with some intention to understand the topic ${ }^{11}$.
These initial results suggest that across the individuals interviewed there was a typical spread of approaches evident. However, there were higher instances of characteristics which related to surface and strategic approaches. While all groups completed the task set, it is worth noting that only one of the four groups successfully solved the problem in terms of relating their laboratory results back to the original problem. It is acknowledged and recognised that this may be as a result of the problem design and delivery since, as mentioned earlier, students will adapt their approach depending on the demands of the teaching, learning and assessment environment.

\section{...they noted that novices orga nised their knowledge about problems according to surface features of their problem statements... while experts organise knowledge based on deeperfeatures of the problem statement, such as the presence of particular forces.}

However, when further analysing the above, it was noted that generally those students that displayed characteristics of a deep approach were from the same group and it was this group that were successful in terms of solving the original problem and displayed the more expert-like characteristics. This provides some evidence for a relationship between a deep approach and more-expert problem-solving ability. Video and further analysis of the observation data will allow more in-depth study into the complex relationships at play here. 


\section{Conclusion}

Overall, it was shown that students revealed novice-like problem solving strategies and surface approaches to learning. However, one group revealed more expert-like characteristics, coupled with a deep approach, with this group successfully solving the problem. One implication of this study is that we need to be more aware of the learning approaches of our students, as well as their subject knowledge, as they enter into higher education. Teaching staff need to carefully scaffold such problem-based learning opportunities and provide opportunities for them to experience collaborative group work and develop other related skills. This should enable the students to take full advantage of more student-centred approaches, such as problem-based learning. This is particularly relevant in the context of easing the transition from secondary to higher education in the sciences ${ }^{12}$.

This research has been funded by a HEA Physical Sciences Centre Development Project grant.

\section{References}

1. Overton, T.L., Byers, B. and Seery, M.K. (2009) Contextand problem-based learning in higher level chemistry education. In Ingo Eilks and Bill Byers (Eds.) Innovative Methods of Teaching and Learning Chemistry in Higher Education. p. 43-59

2. Allen, D.E., Donham, R.S. and Bernhardt, S.A. (2011) Problem-based learning. New Directions in Teaching and Learning. Volume 2011, Issue 128 p.21-29

3. Cartrette, D.P. and Bodner, G.M. (2010) Non-Mathematical Problem Solving in Organic Chemistry. Journal of Research in Science Teaching, 47 (6) p. 643-660

4. Benner, P. (1984). From novice to expert: Excellence and power in clinical nursing practice. Menlo Park: AddisonWesley, pp. 13-34

5. Dreyfus S. E., and Dreyfus H.L. (1980) A five stage model of the mental activities involved in directed skill acquisition. California University Berkeley Operations Research Center [Online]; 1980. Available from: <www.dtic.mil/dtic/tr/fulltext/u2/a084551.pdf> (Accessed 17 May 2012)

6. Elio, R. and Scharf, P.B., (1990) Modeling Novice-to-Expert Shifts in Problem-Solving Strategy and Knowledge Organisation. Cognitive Science, 14, 579-639

7. Peña, A. (2010) The Dreyfus model of clinical problemsolving skills acquisition: a critical perspective. Medical Education Online, 15

8. Biggs, J. (1987) Student approaches to learning and studying. Melbourne: Australian Council for Educational Research.

9. Entwistle, N. (1987) Understanding classroom learning. London: Hodder and Stoughton

10. Kelly, O. and Finlayson, O.E. (2007) Providing solutions through problem-based learning for the undergraduate 1st year chemistry laboratory. Chemistry Education Research and Practice, 8 (3) 347-361

11. Lublin, J. (2003) Deep, surface and strategic approaches to learning. Centre for Teaching and Learning. Good Practice in Teaching and Learning. University College Dublin. [Online] Available at: $<$ www2.warwick.ac.uk/services/ldc/development/pga/part_1/ resources/2a_deep_surfacestrategic_approaches_to_learni ng.pdf> (Accessed 15 October 2011)

12. Kelly, O.C. and Finlayson, O.E. (2010) Easing the transition from secondary school to higher education through recognition of the skills of our students. New Directions in the teaching of Physical Sciences, 6 (51-55) 